\title{
Changes in Diet and Lifestyle may Lower the Risk of Type 1 Diabetes Mellitus in Children-Environmental Factors Influencing Type 1 Diabetes Mellitus Morbidity
}

Katarzyna Korzeniowska*, Ilona Derkowska, Magdalena Zalinska, Aleksander Remesz, Aldona Kmiec and Malgorzata Mysliwiec

Medical University of Gdansk, Gdansk, Poland

\begin{abstract}
Introduction: A significant increase in the incidence of type 1 diabetes has been observed. Environmental factors are considered to play a major role in aetiology of type 1 diabetes.

Material and methods: The study included 153 patients aged 0-18 years old: 75 admitted to Department of Paediatrics, Diabetology and Endocrinology due to newly diagnosed type 1 diabetes (DM1) and 78 admitted to the Paediatric Hospital "Polanki" in the years 2010- 2015. The parents were asked to fill in a questionnaire about environmental factors and development of their children. Statistical analyses were performed using STATISTICA 12 package, using T-student test, Chi-square test (with Yates modification) and U Mann-Whitney test. respectively). Moreover, a significant reduction of DM1 risk was observed in children vaccinated with combined vaccines and recommended vaccinations against Streptococcus pneumoniae and rotaviruses $(59 \%$ to $26,6 \%, p=0.001 ; 60 \%$ to $25,3 \%, p<0.001)$. No difference was found between the groups concerning: body weight in the second year of life, length of breast feeding, gluten introduction, viral infections, source of drinking water or way of heating.

Conclusions: Finding environmental factors that cause increase of incidence of type 1 diabetes is relevant for the further studies and prevention of this illness. Limiting highly processed food and sweet beverages consumption, reducing 'screen time' as well as combined vaccinations may have an important influence on lowering DM1 risk.

Results: Children from the Study Group ate significantly more candies, chocolate bars and drank more sweet beverages prior to the diagnosis of DM1 (72\% to $55 \%, p=0.03 ; 80 \%$ to $42 \%, p<0.0006 ; 60 \%$ to $40 \%, p=0.01$ respectively). Children with DM1 spent more time in front of TV set $(53 \%$ to $36 \%, p=0.06 ; 2,26$ hours to 1,8 hours, $\mathrm{p}=0.02$.
\end{abstract}

Keywords: Type 1 diabetes mellitus; Environmental factors; Vaccinations; Sedentary lifestyle; Diet; Children

\section{Introduction}

Progressive, constant increase in the incidence of type 1 diabetes mellitus is being observed among children in Poland since 1989 [1]. Until the very end of XX century Poland was supposed to be the country of the low incidence of type 1 diabetes. However, between 1998 and 2006 Mysliwiec et al. proved that the incidence rate of type 1 diabetes among children under 15 in Pomeranian Voivodeship in Poland rose unexpectedly from 10,4 to 20,5 per 100.000 children [1]. According to Jarosz-Chobot et al. the prognosis for the next decade is even more threatening, as the estimate suggests at least four times higher incidence risk between 2005 and 2025, influencing mostly the youngest children [2].

Moreover, type 1 diabetes mellitus is more frequently being diagnosed in patients with low genetic susceptibility [3]. Thus, environmental factors seem to play a very important role in triggering or initiating the autoimmune response in the beta cells of the pancreas [4-7].

There are several existing hypotheses, which try to connect different environmental factors with rising incidence of type 1 diabetes. One of the most interesting theories is the hygiene hypothesis. It was mentioned for the first time by Strachan [8], and revealed that exposure to plenty of infectious agents, especially in the earliest childhood, may function as a protective factor against a variety of diseases, such as diabetes type 1 [9]. In DIAMOND Project Group a gradual decrease in the incidence of mumps, rubella, tuberculosis and enterovirus infections was contrasted with rising morbidity to the illnesses influencing human autoimmune system [10].
On contrary, another worth mentioning theory is the viral hypothesis stating that some viruses (such as enteroviruses, rubella virus, mumps virus, rotaviruses) may trigger or accelerate the autoimmune response and lead to the outburst of type 1 diabetes [11-21]. However, the evidence-based data concerning the influence of viral infections on the incidence of type 1 diabetes are still limited.

Another hypothesis finds the negative correlation between the length of breast-feeding and the risk of developing type 1 diabetes [22], which however was so far confirmed only in genetically prone children [23].

There are also data stating that highly processed food can add to the problem by accelerating the autoimmunological response [24]. On the other hand, it's worth mentioning that according to the work of Scicchitano et al. [25] nutraceuticals (functional food) can lower the risk of metabolic problems, such as atherosclerosis.

Finally, it is almost impossible that a single factor could be responsible for the rising number of newly diagnosed with type

${ }^{*}$ Corresponding author: Katarzyna Korzeniowska, Medical University of Gdansk, Gdansk, Poland, Tel: +90136528623; E-mail: kkorzeniowska@gumed.edu.pl

Received November 08, 2016; Accepted November 21, 2016; Published November 25, 2016

Citation: Korzeniowska K, Derkowska I, Zalinska M, Remesz A, Kmiec A, et al (2016) Changes in Diet and Lifestyle may Lower the Risk of Type 1 Diabetes Mellitus in Children-Environmental Factors Influencing Type 1 Diabetes Mellitus Morbidity. J Diabetes Metab 7: 716. doi: 10.4172/2155-6156.1000716

Copyright: $\odot 2016$ Korzeniowska K, et al. This is an open-access article distributed under the terms of the Creative Commons Attribution License, which permits unrestricted use, distribution, and reproduction in any medium, provided the original author and source are credited. 
Citation: Korzeniowska K, Derkowska I, Zalinska M, Remesz A, Kmiec A, et al. (2016) Changes in Diet and Lifestyle may Lower the Risk of Type 1 Diabetes Mellitus in Children-Environmental Factors Influencing Type 1 Diabetes Mellitus Morbidity. J Diabetes Metab 7: 716. doi: $10.4172 / 2155-6156.1000716$

Page 2 of 4

1 diabetes. Moreover, in various regions in the world, the cause could differ. Therefore, we decided to perform a study based on the population of polish children from Pomeranian Voivodeship to try to find environmental factors influencing the risk of type 1 diabetes.

\section{Material and Methods}

A case-control study was carried out in the Department of Paediatrics, Diabetology and Endocrinology of Medical University of Gdansk and Paediatric Hospital Polanki” between 2010 and 2015. Informed consent was obtained from all patients. Ethics Committee from Medical University of Gdansk agreed to the investigation.

The study group comprised of 75 children aged 2,5-17,7 years (53\% male, $47 \%$ female) who were newly diagnosed with type 1 diabetes mellitus (T1DM) in accordance with the criteria of the American Diabetes Association [8].

The Control Group consisted of 78 healthy children aged 1,6-17,9 years without any medical history of elevated blood glucose levels or taking diabetic medication matched by age and gender to the studied population.

The data was gathered by trained health care professionals by asking the parents to fill in questionnaires about environmental factors (eating habits, lifestyle, source of drinking water, heating system, pets) and early development (weight at 2 years of age, vaccinations, infections, antibiotics) of their children.

\section{Statistical analyses}

Student's t test was used to measure the significance of differences between mean values of two continuous variables. For the comparison of unpaired data, the Mann-Whitney U-test was used. P-Values of $<0.05$ were considered significant. Data were analysed using STATISTICA 12 package (Statsoft, Tulsa, OK, USA).

\section{Results}

Clinical data of 75 children with T1DM and their 78 healthy peers, who participated in the study are summarized in Table 1.

\section{Neonatal risk factors}

There was no difference in either birth weight and length, gestation length as well as weight and length of the children at 48 months of age, length of breast feeding or gluten introduction into the diet between the T1DM and the Control Group.

\section{Infections}

Groups did not differ while number of viral infections (chicken pox, flu, mumps, rotaviruses), use of antibiotics were compared (Figure 1).

\section{Vaccinations}

In the group of healthy children (Control Group), combined vaccinations as well as suggested vaccinations against rotaviruses and Streptococcus pneumonia were significantly more often used in comparison to the T1DM Group ( $59 \%$ to $26,6 \%, \mathrm{p}=0.001 ; 60 \%$ to $25,3 \%, \mathrm{p}<0.001$ respectively) (Figure 2 ).

\section{Dietary habits}

Patients from the Study Group ate significantly more candies, chocolate bars and drank more sweet beverages prior to the diagnosis of type 1 diabetes mellitus ( $72 \%$ to $55 \%, \mathrm{p}=0.03 ; 80 \%$ to $42 \%, \mathrm{p}<0.0006$; $60 \%$ to $40 \%, \mathrm{p}=0.01$ respectively) (Table 2 ).

\section{Lifestyle}

Comparing the use of media and electronic devices we found out that patients from T1DM Group much more frequently had TV sets in their rooms and well as they spent significantly more hours in front of TV screen ( $53 \%$ to $36 \%, p=0.06 ; 2,26$ hours to 1,8 hours, $\mathrm{p}=0.02$ respectively) (Table 2 ).

No differences were seen between the groups when the source of drinking water or heating system were compared.

\section{Discussion}

As the incidence of type 1 diabetes mellitus constantly grows, the

\begin{tabular}{|c|c|c|c|}
\hline Particulars & T1DM (n=75) & NoDM $(\mathbf{n = 7 8})$ & $\mathbf{p}$-value \\
\hline Age (years, mean) & 12 & 11.5 & $\mathrm{p}=0.43$ \\
\hline Sex (male:female, \%) & $53 \%: 47 \%$ & $52 \%: 48 \%$ & $\mathrm{p}=0.92$ \\
\hline Birth weight, mean (g) & 3505 & 3407 & $\mathrm{p}=0.26$ \\
\hline Birth length, mean (cm) & 55.4 & 54.9 & $\mathrm{p}=0.55$ \\
\hline Gestation length (weeks, mean) & 39.8 & 39.2 & $\mathrm{p}=0.11$ \\
\hline Weight at 48 months (kg, mean) & 13.8 & 14 & $\mathrm{p}=0.87$ \\
\hline Length at 48 months (cm, mean) & 91.1 & 92 & $\mathrm{p}=0.22$ \\
\hline Breast feeding (months, mean) & 7.3 & 6.9 & $\mathrm{p}=0.83$ \\
\hline Gluten Introduction (months, mean) & 6.8 & 7.4 & $\mathrm{p}=0.19$ \\
\hline
\end{tabular}

Table 1: Clinical characteristics of the Study Group (T1DM) and the Control group (noDM).

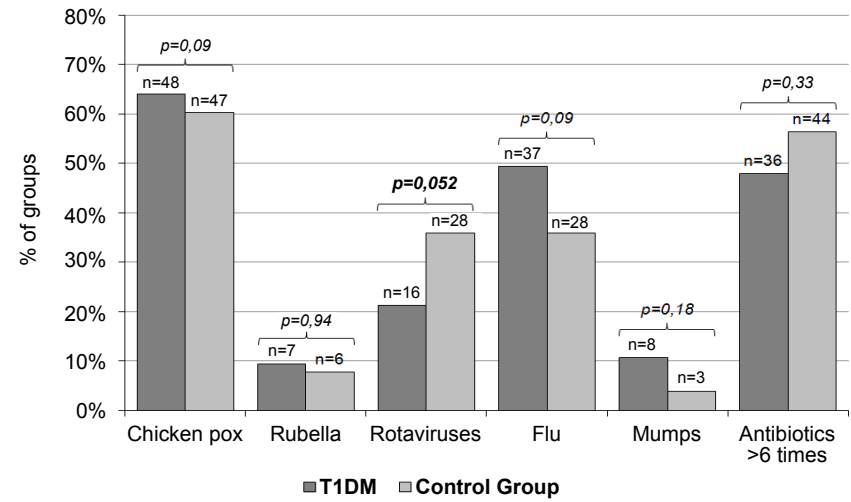

Figure 1: Comparison of use of antibiotics and infections between the groups.

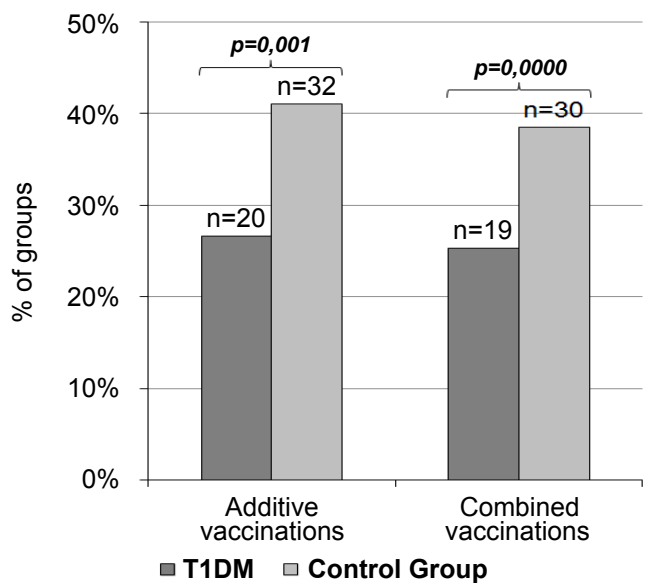

Figure 2: Use of combined vaccinations and additive vaccinations (rotaviruses and streptococcus pneumoniae) in T1DM and Control Group $(\mathrm{p}<0.005)$ 
Citation: Korzeniowska K, Derkowska I, Zalinska M, Remesz A, Kmiec A, et al. (2016) Changes in Diet and Lifestyle may Lower the Risk of Type 1 Diabetes Mellitus in Children-Environmental Factors Influencing Type 1 Diabetes Mellitus Morbidity. J Diabetes Metab 7: 716. doi: $10.4172 / 2155-6156.1000716$

Page 3 of 4

\begin{tabular}{|c|c|c|c|}
\hline Particulars & T1DM (n=75) & NoDM $(\mathbf{n}=\mathbf{7 8})$ & $\mathbf{p}-\mathbf{v a l u e}$ \\
\hline TV set in the bedroom (yes) & 40 & 28 & $\mathrm{P}=0.06$ \\
\hline Hours spent in front of TV set & 2.26 & 1.8 & $\mathrm{P}=0.02$ \\
\hline Hours spent in front of computer & 1.3 & 1.3 & $\mathrm{P}=0.5$ \\
\hline Sweet beverages (yes) & 45 & 31 & $\mathrm{P}=0.01$ \\
\hline Candies (yes) & 54 & 43 & $\mathrm{P}=0.03$ \\
\hline Chocolate bars (yes) & 60 & 42 & $\mathrm{P}<0.005$ \\
\hline Central heating (yes) & 33 & 34 & $\mathrm{P}=0.95$ \\
\hline Waterworks (yes) & 67 & 69 & $\mathrm{P}=0.93$ \\
\hline
\end{tabular}

Table 2: Lifestyle and dietary habits comparison between T1DM and Control group.

search for environmental factors influencing the risk of the disease becomes more important. However, existing data gives us very often conflicting findings regarding the problem [9-11,14].

In our work, we found some evidence of hygiene hypothesis $[18,19]$, as the children with type 1 diabetes more seldom suffered from rotavirus infections during the first year of life in comparison to their healthy peers. Similarly, Bach at al. determined that infections in the early childhood may protect from autoimmune diseases [24].

On contrary, there are limited data about protective issue of vaccinations lowering the risk of type 1 diabetes mellitus (16). Most of the authors find no evidence of an association between routine vaccinations and childhood type 1 diabetes [17].

However, in his newest article, McKinnon et al. [18] states that vaccinations could nowadays not only prevent from infections, but also function as potential immunologic therapy for patients with autoimmune diseases [25].

Our findings very clearly show that the vaccinations against rotaviruses and Streptococcus pneumoniae lowered the risk of type 1 diabetes in our paediatric population. Data gathered in the study seem to be promising, however further investigations on bigger group of patients would be advisable.

Secondly, presented work concentrates on the dietary habits and lifestyle of the patients with newly diagnosed type 1 diabetes in comparison to their healthy peers. In Medical Databases, there are plenty of abstracts about the influence of „screen time” (time spent in front of TV or computer screen) or improper eating habits on insulinresistance and obesity [26]. Longer screen time" also seems to worsen the metabolic control of the patients already suffering from type 1 diabetes $[27,28]$.

Thus, the data about the influence of media-consumption and dietary habits on the risk of type 1 diabetes are still limited.

In our study, we determined that patients from T1DM Group spent significantly more time in front of TV set, as well as the number of children having TV sets in their own room was bigger in the T1DM Group.

As far as the diet is concerned, Lamb at al. claimed that a diet overloaded with carbs can exacerbate the progression from islet autoimmunity to overt type 1 diabetes [12]. Our study seems to confirm this thesis, as we found out that the patients suffering from type 1 diabetes ate more unhealthy sweets (candies, chocolate bars) and drank more sugar-sweetened beverages prior to the diagnosis.

Nevertheless, it's worth mentioning the role of family history in developing type 1 diabetes. According to Mysliwiec et al. [1] the risk of developing diabetes mellitus type 1 was three fold higher in the families when the father or siblings suffered from the same disease.

Some authors also revealed that insulin resistance in the family could add to risk of the development of diabetes mellitus [29]. However, in our study we couldn't confirm these data, as in a vast majority of our patients the family history was insignificant.

\section{Conclusions}

Finding environmental factors that cause increase of incidence of type 1 diabetes is relevant for the further studies and prevention of this illness. Limiting highly processed food and sweet beverages consumption, reducing the time spent in front of TV screen as well as promoting combined vaccinations may have an important influence of lowering the risk of type 1 diabetes mellitus.

\section{References}

1. Mysliwiec M, Balcerska A, Zorena K, Jedrzejczyk A, Malinowska E, et al. (2007) Type 1 diabetes in Polish children. Polish j of Environ Stud 16: 109-112.

2. Jarosz-Chobot P, Polanska J, Szadkowska A, Kretowski A, BandurskaStankiewicz E, et al. (2011) Rapid increase in the incidence of type 1 diabetes in Polish children from 1989 to 2004, and predictions for 2010 to 2025 . Diabetologia 54: 508-515.

3. Fourlanos S, Varney MD, Tait BD (2008) Rising incidence of type 1 diabetes is accounted for by cases with lower-risk human leukocyte antigen genotypes. Diab Care 31: 1546-1549.

4. The Teddy Group (2007) The environmental Determinants of Diabetes in the Young (TEDDY) Study: study design. Pediatr Diab 8: 286-298.

5. Gourrian $P(2000)$ Infections and vaccinations as risk factors for childhood type I (insulin-dependent) diabetes mellitus: a multicentre case-control investigation. EURODIAB Substudy 2 Study Group. Diabetologia 43: 47-53.

6. Ahadi M, Tabatabaeiyan M, Moazzami K (2011) Association between environmental factors and risk of type 1 diabetes - a case-control study. Endokrynol Pol 62: 134-137.

7. Hummel S, Pflüger M, Hummel M, Bonifacio E, Ziegler AG (2011) Primary dietary intervention study to reduce the risk of islet autoimmunity in children at increased risk for type 1 diabetes: the BABYDIET study. Diabetes Care 34: 1301-1305.

8. American Diabetes Association (2016) 2. Classification and Diagnosis of Diabetes. Diabetes Care 39 Suppl 1: S13-22.

9. Knip M, Virtanen S, Akerblom H (2002) Am J Clin Nutr 91: 1506S-1513S.

10. Knip M, Simell O (2012) Environmental triggers of type 1 diabetes. Cold Spring Harb Perspect Med 2: a007690.

11. Egro FM (2013) Why is type 1 diabetes increasing? J Mol Endocrinol 51: R1-13

12. Lamb MM, Frederiksen B, Seifert JA, Kroehl M, Rewers M, et al. (2015) Sugar intake is associated with progression from islet autoimmunity to type 1 diabetes: the Diabetes Autoimmunity Study in the Young. Diabetologia 58: 2027-2034.

13. Honeyman MC, Coulson BS, Stone NL, Gellert SA, Goldwater PN, et al. (2000) Association between rotavirus infection and pancreatic islet autoimmunity in children at risk of developing type 1 diabetes. Diabetes 49: 1319-1324.

14. Ludvigsson J, Holmqvist BM, Samuelsson U (2013) Does modern high standard life style cause type 1 diabetes in children? Diabetes Metab Res Rev 29: 161-165.

15. Snell-Bergeon JK, Smith J, Dong F, Baron AE, Barriga K, et al. (2012) Early childhood infections and the risk of islet autoimmunity: the Diabetes Autoimmunity Study in the Young (DAISY). Diabetes Care 35: 2553-2558.

16. Huang J, Ou HY, Lin J, Karnchanasorn R, Feng W, et al. (2015) The Impact of Hepatitis B Vaccination Status on the Risk of Diabetes, Implicating Diabetes Risk Reduction by Successful Vaccination. PLoS One 10: e0139730.

17. Morgan E, Halliday SR, Campbell GR, et al. (2016) Vaccinations and childhood type 1 diabetes mellitus: a meta-analysis of observational studies. Diabetologia 59: 237-243

18. Strachan DP (1989) Hay fever, hygiene, and household size. BMJ 299: 12591260.

19. Kolb H, Elliott RB (1994) Increasing incidence of IDDM a consequence of improved hygiene? Diabetologia 37: 729. 
Citation: Korzeniowska K, Derkowska I, Zalinska M, Remesz A, Kmiec A, et al. (2016) Changes in Diet and Lifestyle may Lower the Risk of Type 1 Diabetes Mellitus in Children-Environmental Factors Influencing Type 1 Diabetes Mellitus Morbidity. J Diabetes Metab 7: 716. doi: 10.4172/2155-6156.1000716

20. Diamond Project Group (2006) Incidence and trends of childhood Type 1 diabetes worldwide 1990-1999. Diabet Med 23: 857-866.

21. Honeyman MC, Stone NL, Falk BA, Nepom G, Harrison LC (2010) Evidence for molecular mimicry between human $\mathrm{T}$ cell epitopes in rotavirus and pancreatic islet autoantigens. J Immunol 184: 2204-2210.

22. Borch-Johnsen K, Joner G, Mandrup-Poulsen T, Christy M, ZachauChristiansen B, et al. (1984) Relation between breast-feeding and incidence rates of insulin-dependent diabetes mellitus. A hypothesis. Lancet 2: 10831086.

23. Malcova H, Sumnik Z, Drevinek P, Venhacova J, Lebl J, et al. (2006) Absence of breast-feeding is associated with the risk of type 1 diabetes: a case-control study in a population with rapidly increasing incidence. European Journal of Pediatrics 165: 114-119.

24. Bach JF (2001) Protective role of infections and vaccinations on autoimmune diseases. J Autoimmun 16: 347-353.
25. McKinnon JE, Maksimowicz-McKinnon K (2016) Autoimmune disease and vaccination: impact on infectious disease prevention and a look at future applications. Transl Res 167: 46-60.

26. Hardy LL, Denney-Wilson E, Thrift AP, Okely AD, Baur LA (2010) Screen time and metabolic risk factors among adolescents. Arch Pediatr Adolesc Med 164: 643-649.

27. Galler A, Lindau M, Ernert A, Thalemann R, Raile K (2011) Associations Between Media Consumption Habits, Physical Activity, Socioeconomic Status, and Glycemic Control in Children, Adolescents, and Young Adults With Type 1 Diabetes. Diabetes Care 11: 2356-2359.

28. Scicchitano P, Cameli M, Maiello M, Amedeo P, Modesti, et al. (2014) Nutritional elements. Journal of Functional Foods 6: 11-32

29. Ciccone MM (2014) Endothelial Function in Pre-Diabetes, Diabetes and Cardiomyopathy: A review. J Diabetes Metab 5: 364 